\title{
Sex and gender in lung health and disease: more than just Xs and Ys
}

\author{
Jason Weatherald $\mathbb{1}^{1,2}$, Renata L. Riha $\mathbb{1}^{3,4}$ and Marc Humbert $\mathbb{\circledR}^{5,6,7}$
}

${ }^{1}$ Dept of Medicine, Division of Respirology, University of Calgary, Calgary, AB, Canada. ${ }^{2}$ Libin Cardiovascular Institute, University of Calgary, Calgary, AB, Canada. ${ }^{3}$ Dept of Sleep Medicine, Royal Infirmary of Edinburgh, Edinburgh, UK. ${ }^{4}$ Centre for Clinical Brain Sciences, University of Edinburgh, Edinburgh, UK. ${ }^{5}$ Faculty of Medicine, Université Paris-Saclay, Le Kremlin-Bicêtre, France. ${ }^{6}$ INSERM UMR_S 999 (Pulmonary Hypertension: Pathophysiology and Novel Therapies), Hôpital Marie Lannelongue, Le Plessis-Robinson, France. ${ }^{7}$ Dept of Respiratory and Intensive Care Medicine, French Pulmonary Hypertension Reference Center, Hôpital Bicêtre, Assistance Publique-Hôpitaux de Paris (AP-HP), Le Kremlin-Bicêtre, France.

Corresponding author: Jason Weatherald (Jason.Weatherald@ahs.ca)

Shareable abstract (@ERSpublications)

A new series explores the role of sex and gender-related factors in respiratory physiology, lung health, and across respiratory diseases https://bit.ly/3mPOBVF

Cite this article as: Weatherald J, Riha RL, Humbert M. Sex and gender in lung health and disease: more than just Xs and Ys. Eur Respir Rev 2021; 30: 210217 [DOI: 10.1183/16000617.0217-2021].

Copyright $\odot$ The authors 2021

This version is distributed under the terms of the Creative Commons Attribution NonCommercial Licence 4.0. For commercial reproduction rights and permissions contact permissions@ersnet.org

Received: 28 Sept 2021 Accepted: 8 Oct 2021

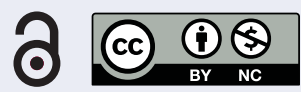

Every nucleated human cell carries sex chromosomes and every person has a gender. These terms "sex" and "gender" are often used interchangeably and incorrectly in the scientific literature, but they mean different things: sex is a biological attribute associated with physical and physiological features determined by chromosomes, hormones, anatomy and gene expression; whereas gender is a sociocultural construct based on expressions of identity, behaviours and social roles [1]. Thus, sex and gender-related factors can both influence health and disease via distinct but intersecting mechanisms. There are important sex differences in lung development that start in utero and during childhood, which ultimately influence respiratory function in adulthood. Women are predisposed to higher rates of several pulmonary diseases such as asthma and pulmonary arterial hypertension. Gender-related factors can also influence pulmonary disease in a variety of ways, including gender differences in occupational exposures, health-seeking behaviours or access to healthcare, and other behaviours such as tobacco use.

A new series of articles starts in this issue of the European Respiratory Review that covers topics on sex and gender in respiratory physiology, health, and disease. Two articles discuss the basis of sex differences in respiratory structure and function, and the mechanisms of sex differences in exercise physiology, with important analyses of the physiological effects of pregnancy on the respiratory system and the implications of exogenous sex hormones [2, 3]. Somayaji and Chalmers [4] provide an overview of sex and gender as health determinants and their associations with respiratory diseases, with a focus on airway diseases like COPD, asthma, and bronchiectasis. Chowdhury et al. [5] take a deeper dive into the literature on sex and gender in asthma. An article by KawANo-Dourado et al. [6] addresses sex and gender factors in interstitial lung diseases, but also looks inward at our profession with a commentary on sex and gender in education and academic careers. CHERON et al. [7] review the sex differences in pulmonary vascular physiology and the role of sex and gender in pulmonary arterial hypertension. Finally, Ragavan and Patel [8] provide an overview of sex and gender factors that influence risk, treatment, and outcomes in lung cancer.

The main purpose of this series is to review our understanding, to date, of the role of sex and gender in differences in pulmonary health and disease. However, we also wish to highlight the importance of addressing this issue in the context of our increasing understanding of how large the differences can be, and the failure universally of our world to adapt to them to date. Sex differences in many aspects of life have not been accounted for, from crash test dummies to anti-hypertensive medications, and we cannot assume from trials where largely one sex has been recruited to translate our findings, with the same expected outcomes, to the other sex [9]. This raises but one issue related to the often flawed methods implemented in treatment trials and the universality of their results; something that is finally being 
recognised by the scientific community at large. We hope that you enjoy this series and that it makes you consider these issues in your day-to-day care, as well as in any future research you may be involved with.

Provenance: Commissioned article, peer reviewed.

Conflict of interest: J. Weatherald reports grants or contracts from Janssen and Actelion, consulting fees from Janssen and Actelion, payment or honoraria for lectures, presentations, speakers' bureaus, manuscript writing or educational events from Janssen, support for attending meetings and/or travel from Janssen, and participation on a Data Safety Monitoring Board or Advisory Board for Janssen and Actelion, all outside the submitted work; and being an unpaid committee member for the Pulmonary Hypertension Association of Canada. R.L. Riha reports receiving consulting fees and payment or honoraria for lectures, presentations, speakers' bureaus, manuscript writing or educational events from Jazz Pharmaceuticals, outside the submitted work. M. Humbert has nothing to disclose.

\section{References}

1 Canadian Institutes of Health Research. How to integrate sex and gender into research. https://cihr-irsc.gc.ca/ e/50836.html Date last accessed: 28 September 2021. Date last updated: 21 August 2019.

2 LoMauro A, Aliverti A. Sex and gender in respiratory physiology. Eur Respir Rev 2021; 30: 210038.

3 Dominelli PB, Molgat-Seon Y. Sex, gender and the pulmonary physiology of exercise. Eur Respir Rev 2021; in press [https://doi.org/10.1183/16000617.0074-2021].

4 Somayaji R, Chalmers JD. Just breathe: a review of sex and gender in chronic lung disease. Eur Respir Rev 2021; in press [https://doi.org/10.1183/16000617.0111-2021].

5 Chowdhury NU, Guntur VP, Newcomb DC, et al. Sex and gender in asthma. Eur Respir Rev 2021; in press [https://doi.org/10.1183/16000617.0067-2021].

6 Kawano-Dourado L, Glassberg MK, Assayag D, et al. Sex and gender in interstitial lung diseases. Eur Respir Rev 2021; in press [https://doi.org/10.1183/16000617.0105-2021].

7 Cheron C, McBride SA, Antigny F, et al. Sex and gender in pulmonary arterial hypertension. Eur Respir Rev 2021; 30: 200330.

8 Ragavan M, Patel MI. The evolving landscape of sex-based differences in lung cancer: a distinct disease in women. Eur Respir Rev 2021; in press [https://doi.org/10.1183/16000617.0100-2021].

9 Glezerman M. Gender Medicine: The Groundbreaking New Science of Gender- and Sex-Related Diagnosis and Treatment. London, Overlook Books, 2016. 